\title{
'Haeoreum', A New Hibiscus syriacus Cultivar for Street Trees
}

\author{
Yunmi Park, Seok-Woo Lee, Soon-ho Kwon, and Hae Yun Kwon \\ Department of Forest Bioresources, National Institute of Forest Science, \\ Suwon 16631, Korea
}

Additional index words. artificial cross, breeding, cultivar, national flower tree, ornamental

Unlike most ornamental trees that bloom in spring, Hibiscus syriacus L. (Rose of Sharon), which is the national flower of Korea, has nearly 60 to $100 \mathrm{~d}$ of flowering time from early July to late October, and there are more than 350 varieties of this plant that have been developed worldwide (Ha et al., 2013; Lee, 2013). The varieties of $H$. syriacus are categorized into single or double flowers depending on the number of petals and depending on the color patterns on the petals. They are categorized as 'Baedal' (white petals), 'Dansim' (petal with red-eye zone), and 'Asadal' (red patterns on the edge of petals) (Korea Forest Service, 2008). The Rose of Sharon, which has red or white flower with five petals and a vivid red-eye zone in the center is a symbol of the Korean culture and was symbolically designated in the early 1990s by the Korea Forest Service (Song, 2004).

However, in Korea, the Rose of Sharon has a misinterpreted image of being easily infected with aphids but it is also recognized as a robust tree that can survive in poor soil conditions. It is also widely believed that the flowers are small and not beautiful because they are planted in raw land with poor management (Korea Forest Service, 2008). Moreover, most of the seedlings that are planted in Korea give rise to trees with an obscure origin; but when initially planted, they are managed with no knowledge of the characteristics. Therefore, until they mature and bloom, it is difficult to fully discover the excellence of the flowers (Korea Forest Service, 2008).

Since the 1970s, attempts have been made to develop new varieties with diverse characteristics to improve how the public perceives the Rose of Sharon and to increase the genetic diversity of the breeding groups through artificial interbreeding or by inducing mutations through radiation or chemicals (Ha et al., 2013; Kyung, 2001; Shim et al., 1993; Yu and Yeam, 1987). The National Institute of Forest Science (NIFoS) has been

Received for publication 25 Mar. 2020. Accepted for publication 27 Apr. 2020.

Published online 5 June 2020.

H.Y.K. is the corresponding author. E-mail: kwonhy05@korea.kr.

This is an open access article distributed under the CC BY-NC-ND license (https://creativecommons. org/licenses/by-nc-nd/4.0/). working continuously to enhance the beauty and excellence of this tree through artificial interbreeding, and recently NIFoS has developed more than 20 new varieties, such as $H$. syriacus 'Sŏndŏk', H. syriacus 'Chilbo', and $H$. syriacus 'Kojumong'. They are also focusing on developing new types that are easier to grow instead of focusing on the color of the flower (Korea Forest Service, 2008).

As of 2010, local governments, public organizations, and schools of all levels in Korea have been increasingly demanding the development of gardens that include the Rose of Sharon trees and wanting to plant them as roadside trees to stimulate a sense of national pride (Kwon et al., 2012). This research developed a new cultivar to be planted as street trees. Furthermore, to meet these recent expectations of the Rose of Sharon, the new cultivar has a faster tree growth and is visually appealing because of its larger flowers with thicker red-eye zones.

\section{Origin}

A new cultivar, H. syriacus 'Haeoreum', was developed at NIFoS in 2014. It was initially derived from an artificial crossing between $H$. syriacus 'Pulkkot' and $H$. syriacus 'Wonhwa' in 2006. H. syriacus 'Pulkkot' was selected among native Rose of Sharons in 1983, a seed parent with a large red flower and a red-eye zone, having a vigorous growth characteristic. Later, $H$. syriacus 'Wonhwa' as a pollen parent was selected among native Rose of Sharons in 1990, having a large white flower with a red-eye zone and strong apical dormancy. Then in Apr. 2007, 45 seeds (obtained by artificial crossing) were sown in the same nursery and 30 seedlings from them were obtained through germination. In Aug. 2009 , five lines were selected for the development of a new cultivar with fast growth; the flower shapes, the color of petals, the presence of red-eye zone, and period of flowering were assessed. The first selection lines were propagated by stem cutting, and then one line among them was chosen through a major characteristics evaluation. In the experimental field, the line was grown in rows with $1.2 \mathrm{~m}$ between the trees; they were irrigated and fertilized in the same way as other trees. By 2014, the selected line was grown and tested for the stability of major characteristics, and finally, the line was developed as a cultivar (Fig. 1).

\section{Description}

Morphological characteristics such as flower color, flower size, petal color pattern, bloom period, and leaf characteristics of the crossings were measured. We evaluated 20 to 30 flowers and leaves samples from each of five trees. The color of the flowers was described according to the Royal Horticultural Society (RHS) Color Charts (Royal Horticultural Society Flower Council of

\begin{tabular}{|c|c|c|c|c|c|}
\hline Year & 2006 & $2007 \sim 2008$ & $2009 \sim 2011$ & $2012 \sim 2013$ & 2014 \\
\hline \multirow[t]{5}{*}{ Generation } & $\begin{array}{l}\text { Artificial } \\
\text { crossing }\end{array}$ & $\begin{array}{l}\text { Seedling } \\
\text { (F1) }\end{array}$ & $\mathrm{V}_{1}$ & $\mathrm{~V}_{2}$ & A new cultivar \\
\hline & $\begin{array}{l}\text { Pulkkot } \\
\text { ((q) }\end{array}$ & $\begin{array}{l}\text { KFRI- } \\
\text { PW01 }\end{array}$ & KFRI-PW01 & KFRI-PW01 & $\begin{array}{l}\text { KFRI-PW01 = } \\
\text { 'Heaoreum' }\end{array}$ \\
\hline & & & KFRI-PW03 & & \\
\hline & $\mathrm{x}$ & $\begin{array}{l}\text { KFRI- } \\
\text { PW02 }\end{array}$ & KFRI-PW06 & & \\
\hline & $\begin{array}{c}\text { Wonhwa } \\
\left(\delta^{\lambda}\right)\end{array}$ & . & KFRI-PW10 & & \\
\hline
\end{tabular}

KFRI-PW12

HortScience Vol. 55(7) July 2020 
Table 1. Growth characteristics of a new H. syriacus 'Haeoreum'.

\begin{tabular}{lccccc}
\hline Cultivar & Age of plantlet from cutting & Tree $h t(m)(\mathrm{A})^{z}$ & Tree width $(\mathrm{m})(\mathrm{B})^{\mathrm{z}}$ & Tree form index $(\mathrm{A} / \mathrm{B})^{\mathrm{z}}$ & Direction of branch \\
\hline Haeoreum & 6 years old & $1.7 \pm 0.1 \mathrm{a}$ & $0.6 \pm 0.1 \mathrm{a}$ & $2.7 \pm 0.2 \mathrm{a}$ & Slightly upright \\
Wonhwa (control) & 6 years old & $1.6 \pm 0.2 \mathrm{a}$ & $1.2 \pm 0.1 \mathrm{~b}$ & $1.3 \pm 0.2 \mathrm{~b}$ & Spreading \\
\hline
\end{tabular}

${ }^{\mathrm{z}}$ Means \pm SD done by Student's $t$ test at $P=0.05$ on five plants per cultivar; similar letters within a column indicate no significant difference.
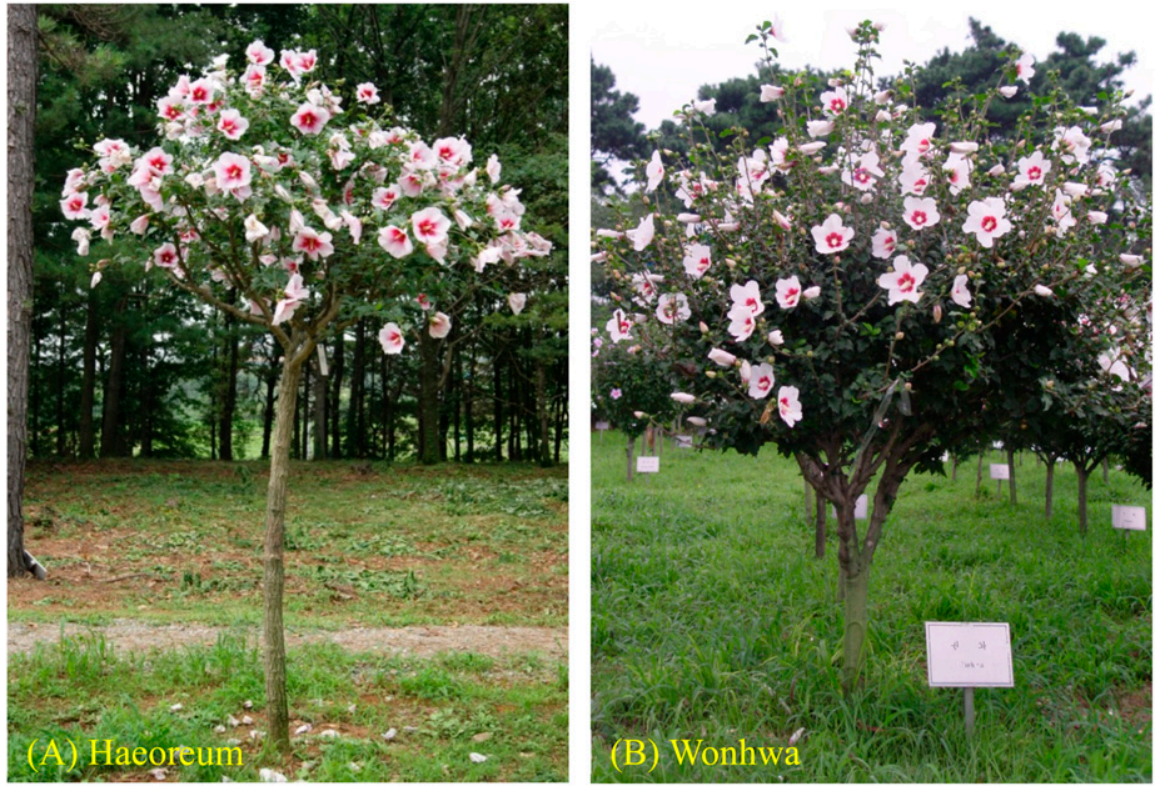

Fig. 2. Comparison of the tree form of an 8-year-old seedling selected as a new H. syriacus 'Haeoreum' (A) and H. syriacus 'Wonhwa' (B), its pollen parent and control cultivar.

Table 2. Flower characteristics of a new H. syriacus 'Haeoreum'.

\begin{tabular}{lccccc}
\hline Cultivar & Flower type & Flower shape & Petal color $\left(\mathrm{RHS}^{\mathrm{z}}\right)$ & $\begin{array}{c}\text { Color of red-eye } \\
\text { zone }\left(\mathrm{RHS}^{\mathrm{z}}\right)\end{array}$ & $\begin{array}{c}\text { Radiation line } \\
\text { on petal }\end{array}$ \\
\hline Haeoreum & Single & Trumpet-shaped & W155D & RP60A & Present \\
Wonhwa (control) & Single & Trumpet-shaped & WN155A & RP60C & Present \\
\hline
\end{tabular}

${ }^{\mathrm{z}}$ RHS color chart (Royal Horticultural Society Flower Council of Holland, 2001).
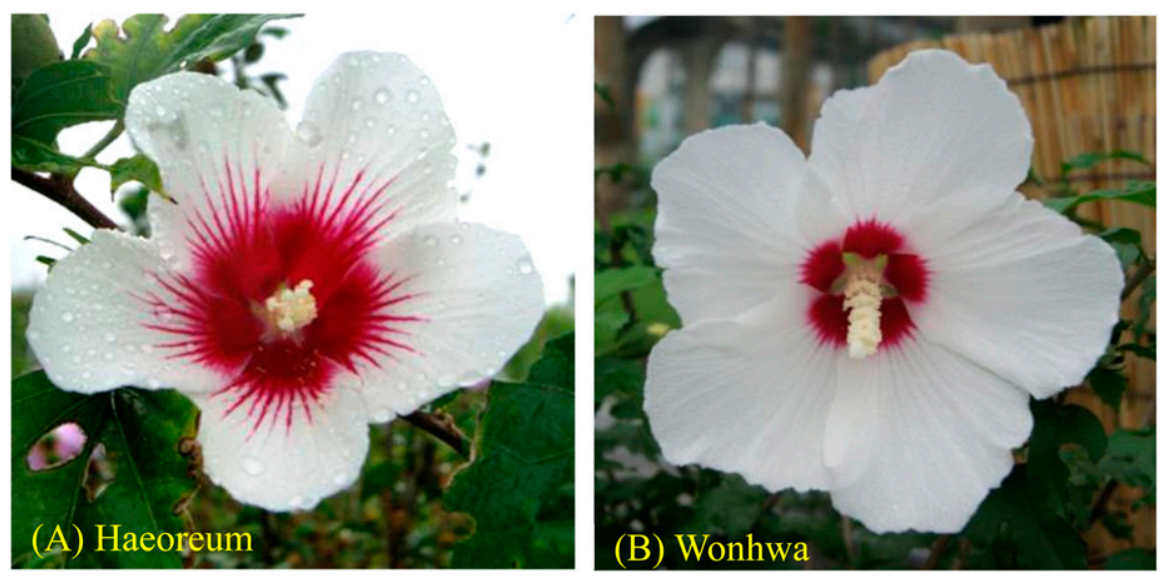

Fig. 3. The flower between a new H. syriacus 'Haeoreum' (A) and H. syriacus 'Wonhwa' (B), its pollen parent and control cultivar.

Holland, 2001). Quantitative indexes of the flowers were measured on the day of full bloom, and the flowering period was recorded according to the dates of the first and the last appearance of the flowers in the tree. The evaluation trial was conducted for 8 years (2007-14), and all these investigated traits were found to be retained in the stem cutting plants that originated from the cultivar. The data were analyzed by SPSS 17.0 (SPSS Inc., Chicago, IL).

When choosing a variety as street trees, it is essential that they have strong, straight, and fast-growing branches. Also, cultivars with large, beautiful flowers and a long blooming period are relatively better in appearance on the roadside as street trees (Langenheim et al., 2020).

A 6-year-old H. syriacus 'Haeoreum' was $1.7 \mathrm{~m}$ tall and $0.6 \mathrm{~m}$ wide, while the $H$. syriacus 'Wonhwa' of the same age was $1.6 \mathrm{~m}$ tall and $1.2 \mathrm{~m}$ wide. Thus, the width of the crown of H. syriacus 'Haeoreum' is narrower than that of $H$. syriacus 'Wonhwa' and displayed an upright form, making them suitable for planting as street trees (Table 1, Fig. 2). The average rate of growth of $H$. syriacus 'Haeoreum' is nearly $90 \mathrm{~cm}$ a year, with the branches at acute angles, therefore the shape of the tree is straight (Fig. 2). On the other hand, the branches of H. syriacus 'Wonhwa' are thick, and these branches occur at a wide, irregular angle (Fig. 2). The peak blooming period of $H$. syriacus 'Haeoreum' is between from early July to late October. The flowering period of the tree investigated in 2018 and 2019 was about $91 \mathrm{~d}$, which is relatively long when compared with the average period of most of other cultivars (60 to $80 \mathrm{~d})$.

H. syriacus 'Haeoreum' had brighter white flowers (RHS W155D), with a larger and thicker red-eye zone (RHS RP60A) when compared with the white flowers (RHS WN155A) of H. syriacus 'Wonhwa', which had a reduced red-eye zone (RHS RP60C) (Table 2, Fig. 3). The flower diameter of $H$. syriacus 'Haeoreum' was $12.9 \pm 0.9 \mathrm{~cm}$, the petal length was $7.5 \pm 0.7 \mathrm{~cm}$, and the petal width was $4.4 \pm 0.5 \mathrm{~cm}$. On the other hand, the flower diameter of the H. syriacus 'Wonhwa' was $12.7 \pm 0.9 \mathrm{~cm}$, the petal length was $8.1 \pm$ $0.8 \mathrm{~cm}$, and the petal width was $6.5 \pm 0.8$ $\mathrm{cm}$. The flower size of $H$. syriacus 'Haeoreum' is the largest of all new cultivars ever developed at NIFoS (Kwon et al., 2014). The ratio of petal length to width of $H$. syriacus 'Haeoreum' was $1.7 \pm 0.1$; therefore, even in full bloom, its petals overlap somewhat more, with incomplete unfolding of the peduncle indicating a trumpet-shape when compared with the flowers of $H$. syriacus 'Wonhwa' (Table 3, Fig. 3). The length of the red-eye spot on petals of $H$. syriacus 'Haeoreum' was $2.6 \pm 0.5 \mathrm{~cm}$. Therefore, the spot zone of this new cultivar is bigger compared with that of $H$. syriacus 'Wonhwa' $(2.0 \pm 0.3)$, and this fact renders $H$. syriacus 'Haeoreum' more appropriate as an ornamental street tree (Table 3). The leaf size of $H$. syriacus 'Haeoreum' is somewhat larger than that of the contrasting H. syriacus 'Wonhwa'. Moreover, the leaf is shaped like a diamond, with a leaf length to width ratio of 1.3 (Table 4). 


\begin{tabular}{|c|c|c|c|c|c|}
\hline \multirow[b]{2}{*}{ Cultivar } & \multirow[b]{2}{*}{ Flower diam $(\mathrm{cm})^{\mathrm{z}}$} & \multicolumn{3}{|c|}{ Petal } & \multirow[b]{2}{*}{ Length of red-eye $(\mathrm{cm})^{z}$} \\
\hline & & Length $(\mathrm{cm})(\mathrm{A})^{\mathrm{z}}$ & Width $(\mathrm{cm})(\mathrm{B})^{\mathrm{z}}$ & Index $(\mathrm{A} / \mathrm{B})^{\mathrm{z}}$ & \\
\hline Haeoreum & $12.9 \pm 0.9 \mathrm{a}$ & $7.5 \pm 0.7 \mathrm{a}$ & $4.4 \pm 0.5 \mathrm{a}$ & $1.7 \pm 0.1 \mathrm{a}$ & $2.6 \pm 0.5 \mathrm{a}$ \\
\hline Wonhwa (control) & $12.7 \pm 0.9 \mathrm{a}$ & $8.1 \pm 0.8 \mathrm{a}$ & $6.5 \pm 0.8 b$ & $1.2 \pm 0.1 \mathrm{~b}$ & $2.0 \pm 0.3 \mathrm{~b}$ \\
\hline
\end{tabular}

${ }^{\mathrm{z}}$ Means \pm SD done by Student's $t$ test at $P=0.05$ on five plants per cultivar (20 flowers/plant); similar letters within a column indicate no significant difference.

Table 4. Leaf characteristics of a new H. syriacus 'Haeoreum'.

\begin{tabular}{|c|c|c|c|c|c|c|c|}
\hline \multirow[b]{2}{*}{ Cultivar } & \multicolumn{6}{|c|}{ Leaf blade } & \multirow[b]{2}{*}{ Petiole length $(\mathrm{cm})^{\mathrm{z}}$} \\
\hline & Shape & Apex & Base & Length $(\mathrm{cm})^{\mathrm{z}}$ & Width $(\mathrm{cm})^{\mathrm{z}}$ & Index $(\mathrm{A} / \mathrm{B})^{\mathrm{z}}$ & \\
\hline Haeoreum & Rhombus & Acute & Cuneate & $7.3 \pm 0.7 \mathrm{a}$ & $5.4 \pm 0.5 \mathrm{a}$ & $1.3 \pm 0.3 \mathrm{a}$ & $1.8 \pm 0.3 \mathrm{a}$ \\
\hline Wonhwa (control) & Rhombus & Acute & Emarginate & $6.3 \pm 0.5 b$ & $3.8 \pm 0.4 \mathrm{~b}$ & $1.6 \pm 0.4 \mathrm{~b}$ & $0.8 \pm 0.2 \mathrm{~b}$ \\
\hline
\end{tabular}

${ }^{\mathrm{z}}$ Means \pm SD done by Student's $t$ test at $P=0.05$ on five plants per cultivar (30 leaves/plant); similar letters within a column indicate no significant difference.

Due to the high demand of light associated with the number of flowers blooming, it is necessary to adjust the number of plants at intervals $(\approx 2-3 \mathrm{~m})$. Even after planting as street trees, the water sprout, the intersecting branches, and the dead branches should be removed to ensure that the inside of the crown is sunny and breezy. Also, half to one-third of the length of the branches should be cut off every year or every other year to maintain the shape of the crown and to facilitate the increase of the number of flowers.

To summarize, this study describes a new cultivar named $H$. syriacus 'Haeoreum', which produces attractive, big-sized flowers and which shows vigorous, fast growth, as well as an upright structure. Therefore, it is suitable to be used as an ornamental tree as well as a street tree.

This cultivar was registered as a new cultivar at the Korea Seed \& Variety Service in 2015 (Grant no. 5758).

\section{Availability}

This cultivar of H. syriacus, 'Heaoreum' is available for research or trials. Requests for samples of the cloned plants may be addressed to Dr. Hae Yun Kwon (e-mail: kwonhy05@korea.kr), National Institute of Forest Science, Suwon, Korea.

\section{Literature Cited}

Ha, Y.M., I.S. Han, and K.S. Kim. 2013. The Rose of Sharon. J. Korean Soc. Hort. Sci. 5:323328.

Kyung, H.Y. 2001. Breeding of single and three way interspecific hybrids among Hibiscus syriacus, interspecific hybrid (H. syriacus $\times$ $H$. paramutabilis), and H. sinosyriacus. Ph.D thesis, Kangwon Univ., Korea.

Kwon, H.Y., S.H. Kim, and H.S. Park. 2012 Growing and management of Hibiscus syriacus, the national flower of Korea. Korea Forest Research Institute (KFRI), Seoul, Korea.

Kwon, H.Y., S.H. Kim, S.J. Shim, and J.I. Nam. 2014. The encyclopedia of the Rose of Sharon breed. Korea Forest Research Institute (KFRI), Seoul, Korea.

Korea Forest Service. 2008. A master plan for more market-friendly and extensive utilization of the national flower. Daejeon, Korea. p. 1-8.

Lee, J.S. 2013. Distribution and status of H. syriacus of the world. Proceedings of the 5th symposium of $H$. syriacus Research Society. Seoul, Korea.

Langenheim, N., M. White, N. Tapper, S.J. Livesley, and D. Ramirez-Lovering. 2020. Right tree, right place, right time: A visual-functional design approach to select and place trees for optimal shade benefit to commuting pedestrians. Sustain Cities Soc. 52:101816, doi: 10.1016/j.scs.2019.101816.

Royal Horticultural Society Flower Council of Holland. 2001. RHS color chart. 4th ed. London, UK.

Song, W.S. 2004. Hibiscus syriacus-What are the characteristics of the flower? Semyeongseogwan, Seoul, Korea.

Shim, K.K., K.H. Kim, and Y.M. Ha. 1993. Characteristics of triploid cultivars 'Diana' and 'Helene' in H. syriacus L. J. Korean Soc. Hort. Sci. 34:54-67.

Yu, T.Y. and D.Y. Yeam. 1987. Korean national flower, Hibiscus syriacus. Hakwon Co., Korea. 